\title{
Evaluating the Flame Retardancy of Shaving Super Bamboo Layer by Layer Self-Assembly With Phytic Acid-Polyethyleneimine
}

\author{
Peng Lin ${ }^{1,2}$, Yingqiu Jiang ${ }^{1}$, Xiaolin $\mathrm{Ru}^{1}$, Wenbo Che ${ }^{1}$, Xiaochun Zhang ${ }^{1}$, Lingfei Ma ${ }^{1}$, \\ Junfeng $\mathrm{Hou}^{1,3 *}$ and Youming $\mathrm{Yu}^{1,3 *}$
}

${ }^{1}$ School of Engineering, Zhejiang A\&F University, Hangzhou, China, ${ }^{2} Z$ honghang Monitoring and Testing Technology Research Institute Co., Ltd., Hangzhou, China, ${ }^{3}$ Zhejiang Provincial Collaborative Innovation Center for Bamboo Resources and HighEfficiency Utilization, Hangzhou, China

\section{OPEN ACCESS}

Edited by:

Yan Zhang,

Zhejiang University, China

Reviewed by:

Weizhao Hu,

University of Science and Technology

of China, China

Seyed Mohsen Seraji,

University of Southern Queensland,

Australia

Hongqiang Yan,

Zhejiang University, China

*Correspondence:

Junfeng Hou

houjunfeng@zafu.edu.cn Youming Yu

yuyouming@zafu.edu.cn

Specialty section:

This article was submitted to

Polymeric and Composite Materials,

a section of the journal

Frontiers in Materials

Received: 20 April 2021

Accepted: 21 June 2021

Published: 16 August 2021

Citation:

Lin $P$, Jiang $Y, R u X$, Che $W$, Zhang $X$, Ma L, Hou J and Yu Y (2021) Evaluating the Flame Retardancy of Shaving

Super Bamboo Layer by Layer Self-

Assembly With Phytic Acid-

Polyethyleneimine.

Front. Mater. 8:697732.

doi: 10.3389/fmats.2021.697732
To improve the flame retardancy of bamboo materials, layer by layer $(L b L)$ self-assembly of phytic acid (PA)-polyethyleneimine (PEI) on the surface of shaving super bamboo specimens with different solution concentrations of PA-PEI and times of LbL selfassembly was completed in this study. Fourier transform infrared analysis results showed that PEI was well assembled to the surface of bamboo specimens by a hydrogen bond with PA as intermediation. The application of PA and PEI significantly promoted the formation of carbon residue, as characterized by simultaneous thermal measurements. Particularly, the peak heat release rate and total heat release rate of bamboo self-assembly with $10 \mathrm{wt} \% \mathrm{PA}$ and $10 \mathrm{wt} \%$ of PEl solution were reduced by 19.36 and $22.3 \%$, respectively. The treated bamboo specimen showed increases of 35.56 and $480.70 \%$ in fire performance index and residual mass, respectively, compared to the control sample. Besides, yields of $\mathrm{CO}$ and $\mathrm{CO}_{2}$ were decreased by 17.77 and $17.07 \%$ in comparison with the control group, respectively. The LbL self-assembly with PA-PEI can effectively improve the flame retardancy of bamboo materials by promoting the formation of a residual char layer.

Keywords: shaving super bamboo, phytic acid (PA), polyethyleneimine (PEI), self-assembly, flame retardancy

\section{INTRODUCTION}

Bamboo presents high application prospects and economic value as a substitute for wood due to its similarity to wood in compositions and structures (Scurlock et al., 2000; Zhang X. et al., 2019; Zhang L. et al., 2020). It is traditionally applied to fabricate bamboo-based panels such as plywood, fiberboard, laminated bamboo board, and particleboard. All of these bamboo-based panels have always maintained an important position in the manufacturing of flooring, furniture, and construction due to their unique excellent characteristics, but their high flammability has significantly limited various applications. Therefore, it is necessary to develop flame retardant bamboo-based panels for their practical applications (Guo et al., 2019; Pope et al., 2019).

Most of the previous studies on the preparation of flame retardants focus on green and sustainable flame retardants (He et al., 2020). As a natural non-toxic compound, phytic acid (PA) is abundant in beans, cereals, and oilseeds (Dusková et al., 2001; Fang et al., 2019; Liu et al., 2021). As a biocompatible, environmentally friendly, non-toxic, and easily available organic acid, the content 
of phosphorus reaches $28 \%$. The phosphorus element makes it a potential green biomass flame retardant. Negative charges were found in the PA solution due to the existence of the special structure that 12 acidic groups were symmetrically connected to a cyclohexanol ring (Jo et al., 2008; Ye et al., 2012; Zeng et al., 2021). The thermal stability and mechanical property of the matrix were declined once combined with PA. It has been reported that the combination of PA and certain metal ions can significantly improve the flame retardant performance of PA (Shen et al., 2016; Fang et al., 2018; Gong et al., 2020). A synergistic effect is observed to generate phosphorus-containing flame retardants with the presence of nitrogen elements, leading to a more excellent flame retardant performance (Nguyen et al., 2013). Therefore, PA is more often combined with some nitrogencontaining compounds such as chitosan, melamine, and polyethyleneimine because the combination results in a synergistic fire-retarding effect once they are used as a flame retardant (Zhang et al., 2014a; Zhang et al., 2014b; Jin et al., 2017; Wang et al., 2019; Zmz et al., 2019). It has been proved that the combination of PA with nitrogen-containing compound will be made into an intumescent flame retardant (IFR) system with PA as an acid source and phosphorus source (Dusková et al., 2001; Zhang et al., 2014a; Jin et al., 2017; Zeng et al., 2021). In addition, a gas source in the IFR system is provided by nitrogen-containing compounds with releasing incombustible gases of $\mathrm{N}_{2}$ and $\mathrm{NO}_{2}$ in the combustion process of composites (Nguyen et al., 2013; Zhang et al., 2014b; Xiong et al., 2019). This flame retardant system is usually evenly dispersed in high molecular polymers to exert a significant flame retardant effect. It has been found that PA is effectively absorbed by the wool fabric and excellent flame retardant performance has been illustrated with the electrostatic interactions between the positively charged amino groups and the negatively charged phytic acid phosphate groups in wool (Cheng et al., 2016a; Cheng et al., 2019).

PA can be effectively combined with cellulose-rich materials to prevent cellulose-rich materials from combusting during the combustion process of materials due to the action of the condensed phase mechanism (Wang et al., 2015; Zhang Z. et al., 2019). However, a further treatment of PA is needed to get a neutral negative charge carried by PA and to make it effectively adhere to the surface of the matrix. Some efforts have been made to prepare an intumescent flame retardant (IFR) solution with PA and uracil to improve the flame retardant performance of the matrix. The IFR solution with PA and uracil has been used to prepare one-step treated wood for excellent flame retardancy. Results revealed that the peak heat release rate, total heat release, smoke production rate, and total smoke production of flame retardant wood were reduced by 41 , 30,61 , and $56 \%$, respectively, compared with natural wood (Zhang Y. et al., 2020).

The IFR system completed by the LbL self-assembly technology has been preliminarily introduced to surface modification treatment of shaving super bamboo in this study. PA is selected to provide an acid source and phosphorus source to improve the flame retardant performance, and polyethyleneimine (PEI) provides a gas source for its high nitrogen content and positive charge in solutions (Liu et al., 2016; Ran et al., 2019; Huo et al., 2021). Besides, an LbL self-assembly method was applied to assemble and install PA to be negatively charged and PEI to be positively charged on the surface of shaving super bamboo to fabricate bamboo materials with excellent flame retardant performance (Laachachi et al., 2011; Laufer et al., 2012; Wang et al., 2017; Fang et al., 2019). Herein, we systematically analyze the effects of PAPEI solution and times of LbL self-assembly on the flame retardancy of bamboo specimens. Besides, PA-PEI LbL selfassembly on the surface of bamboo specimens was analyzed by Fourier transform infrared (FTIR) analysis and simultaneous thermal analysis (STA). Cone calorimeter analysis was completed to investigate further the effect of reagent concentration and times of LbL self-assembly on flame retardant of bamboo specimens LbL self-assembly with PAPEI. This work provides an insight to a better understanding of the flame retardancy of shaving super bamboo LbL selfassembly with PA-PEI.

\section{EXPERIMENTAL SECTION}

\section{Materials}

Shaving super bamboo with demotions of $2000 \mathrm{~mm}$ (length: L) $\times 500 \mathrm{~mm}$ (width: $\mathrm{W}) \times 0.6 \mathrm{~mm}$ (thickness: $\mathrm{T}$ ) was obtained from local Bamboo Industry Co., Ltd. Phytic acid (PA, $\mathrm{C}_{6} \mathrm{H}_{18} \mathrm{O}_{24} \mathrm{P}_{6}$, concentration: $50 \mathrm{wt} \%$ ) with a component of 660 and polyethyleneimine (PEI, $\mathrm{CH}_{2} \mathrm{CH}_{2} \mathrm{NH}, \mathrm{AR}$, concentration: $99 \mathrm{wt}$ $\%)$ with a component of 600 were purchased from Aladdin Biochemical Reagent Co., Ltd., Shanghai, China.

\section{Layer by Layer Self-Assembly of Bamboo Specimens With Phytic Acid-Polyethyleneimine}

Shaving super bamboo was sawn into chips with the dimension of $100 \mathrm{~mm}(\mathrm{~L}) \times 100 \mathrm{~mm}(\mathrm{~W}) \times 0.6 \mathrm{~mm}(\mathrm{~T})$. All of the bamboo chips were evenly divided into three groups with 100 specimens in every group, namely, Group A, Group B, and the control group. The technology of LbL self-assembly with PA-PEI solution was first applied to improve the flame retardancy performance of shaving super bamboo. The PA solution was prepared by mixing PA with deionized water by magnetic stirrers (DF-101S, Shanghai Lichen Instrument Technology Co., Ltd., Shanghai, China) for $20 \mathrm{~min}$ to obtain a homogenized solution at room temperature. The PEI solution was prepared in the same method. Diagrammatic representation of bamboo specimens LbL selfassembly with PA-PEI is illustrated in Figure 1. Bamboo chips in Groups A and B were evenly divided into five groups and marked as $\mathrm{A} 1$ to $\mathrm{A} 5$ and $\mathrm{B} 1$ to $\mathrm{B} 5$, respectively. Before LbL self-assembled with PA-PEI, all of the bamboo chips were immersed in water at $70^{\circ} \mathrm{C}$ for $15 \mathrm{~min}$ and dried at $60 \pm 1^{\circ} \mathrm{C}$ in a drying oven (DKN611, Yamato Scientific Co., Ltd. Tokyo, Japan) for $30 \mathrm{~min}$ and then at $103 \pm 2^{\circ} \mathrm{C}$ until the constant mass is reached when two successive weights do not differ by more than $0.1 \%$. The bamboo specimens 


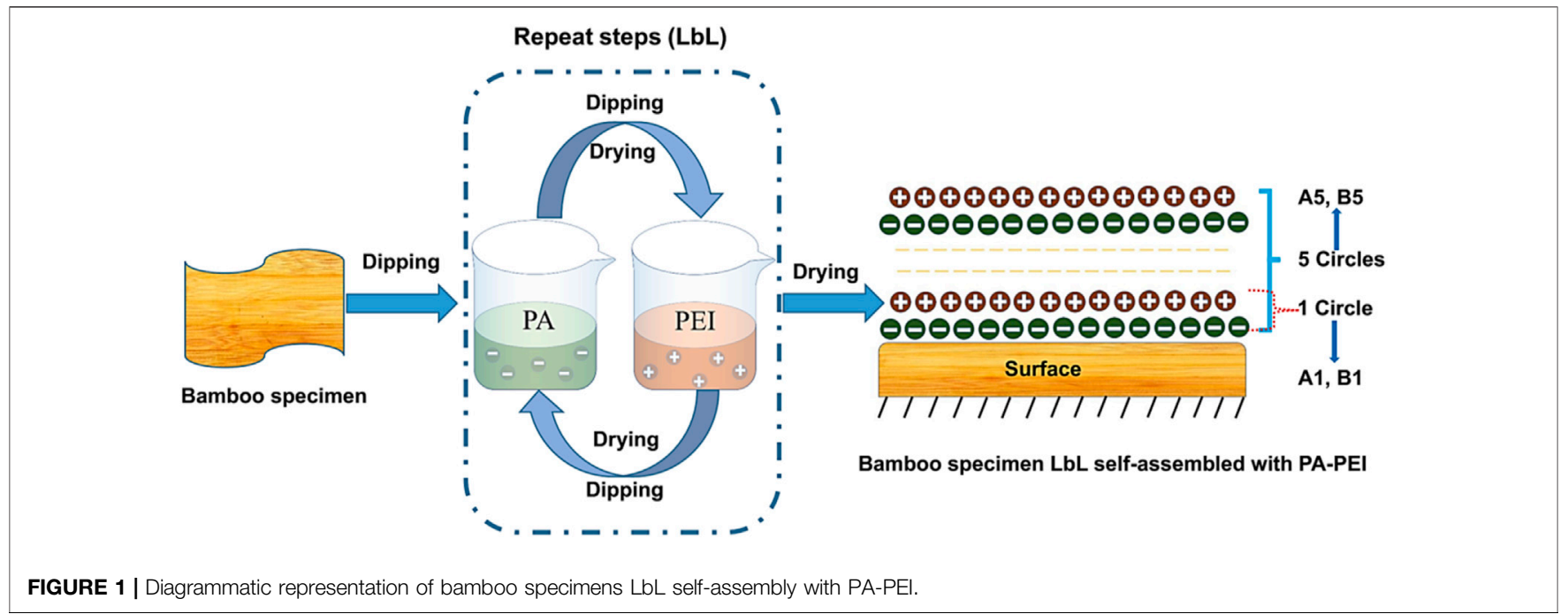

TABLE 1 | Bamboo specimens with different solution concentrations and times of LbL self-assembly with PA-PEI.

Sample no.

PA concentration (\%)

PEI concentration (\%)

Times

of LbL self-assembly

The control
A1
A5
B1
B5

with different solution concentrations and times of LbL selfassembly with PA-PEI are shown in Table 1. Bamboo chips in Group A1 were immersed in $5 \mathrm{wt} \%$ PA solution for $5 \mathrm{~min}$ and then dried at $60 \pm 1^{\circ} \mathrm{C}$ until the moisture content (MC) reduced to $12 \%$. Besides, the bamboo chips were dipped in a $5 \mathrm{wt} \%$ PEI solution for $5 \mathrm{~min}$ and dried at $60 \pm 1^{\circ} \mathrm{C}$ for $30 \mathrm{~min}$ and then at $103 \pm 2^{\circ} \mathrm{C}$ until the constant mass is reached. Bamboo specimens in Group A5 were obtained by repeating the preceding steps five times. Bamboo specimens in Group B were LbL self-assembled by immersing in the $10 \mathrm{wt} \% \mathrm{PA}$ solution and $10 \mathrm{wt} \% \mathrm{PEI}$ solution using the same processing step as Group A. Besides, bamboo specimens in Group B5 were immersed in the $10 \mathrm{wt} \%$ PA solution and $10 \mathrm{wt} \%$ PEI solution five times.

\section{Weight Percent Gain of Bamboo Specimens Self-Assembly With Phytic Acid-Polyethyleneimine}

Weight percent gain (WPG) of bamboo specimens LbL selfassembly with PA-PEI was calculated according to Equation 1:

$$
W P G=\frac{M_{2}-M_{1} \times 100 \%}{M_{1}}
$$

where $M_{1}$ is the ovendry weight of bamboo samples before LbL self-assembly treatment in $\mathrm{g}$ and $\mathrm{M}_{2}$ is the ovendry weight of bamboo samples after LbL self-assembly treatment in $\mathrm{g}$.

\section{Fourier Transform Infrared Analysis of Bamboo Specimens Layer by Layer Self-Assembly With Phytic \\ Acid-Polyethyleneimine}

FTIR analysis of bamboo specimens before and after LbL selfassembly with PA-PEI was completed by spectroscopy (Nicolet 6700, Nicolet Co., Ltd., United States). The investigation was conducted in the $400-4,000 \mathrm{~cm}^{-1}$ frequency range (Zhang $\mathrm{X}$. et al., 2019). The tested specimen for FTIR test was produced by mixing $1 \mathrm{mg}$ bamboo powders (i.e., ovendry state) with a size of sieve opening ranges from 80 to 120 with $99 \mathrm{mg}$ potassium bromide $(\mathrm{KBr})$.

\section{TG-DTA Analysis of Bamboo Specimens Layer by Layer Self-Assembly With Phytic Acid-Polyethyleneimine}

TG-DTA analysis of bamboo specimens before and after LbL selfassembly with PA-PEI was completed by a simultaneous thermal analysis (STA 409 C, NETZSCH Company, German). Ten mg of bamboo powders was placed in an $\mathrm{Al}_{2} \mathrm{O}_{3}$ crucible and measured by heating from $20^{\circ} \mathrm{C}$ to $800^{\circ} \mathrm{C}$ with a heating rate of $10^{\circ} \mathrm{C} / \mathrm{min}$ in the nitrogen atmosphere. 


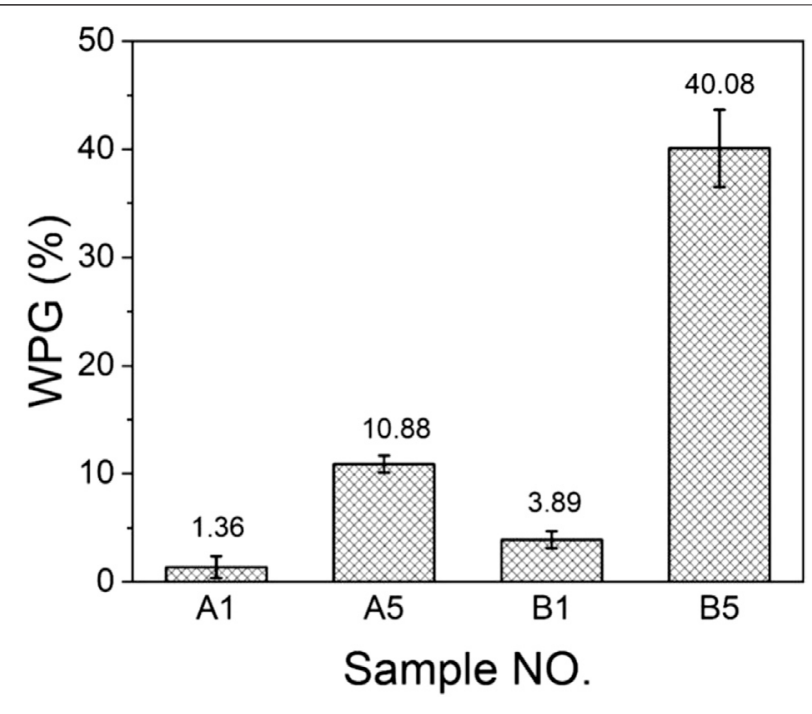

FIGURE 2 | WPG of bamboo specimens at different times of LbL selfassembly with PA-PEI.

\section{Cone Calorimeter Analysis of Bamboo Specimens Layer by Layer Self-Assembly With Phytic Acid-Polyethyleneimine}

The combustion performance of bamboo specimens was measured by a cone calorimeter (Fire Testing Technology Ltd., United Kingdom) in accordance with ISO 5660-1 (Yu et al., 2016; Hou et al., 2017). All specimens with dimensions of $100 \mathrm{~mm}$ (L) $\times 100 \mathrm{~mm}(\mathrm{~W}) \times 6 \mathrm{~mm}(\mathrm{~T})$ were hot-pressed at $100^{\circ} \mathrm{C}$ for $5 \mathrm{~min}$ through laminating shaving super bamboo specimens $(100 \mathrm{~mm}$ (L) $\times 100 \mathrm{~mm}(\mathrm{~W}) \times 0.6 \mathrm{~mm}(\mathrm{~T}))$. Prior to cone calorimeter testing, the tested specimens were conditioned to equilibrium moisture content (EMC) at a controlled environment (Temperature of $23^{\circ} \mathrm{C} ; 50 \%$ relative humidity $(\mathrm{RH})$ ) in a highlow humidity alternating test box (EL-10KA, Espec Corporation, Hudsonville, MI, United States) until the constant mass is reached. The tested specimens were irradiated with an incident heat flux of $50 \mathrm{~kW}$ (Yu et al., 2016; Hou et al., 2017). All the experimental treatments were performed three times with the average values reported.

\section{RESULTS AND DISCUSSION}

\section{Weight Percent Gain of Bamboo Specimens Self-Assembly With Phytic Acid-Polyethyleneimine}

WPG of bamboo specimens before and after LbL self-assembly is illustrated in Figure 2. A gradual increase was observed in WPG with the increasing times of LbL self-assembly as illustrated in Figure 2. A slight increase of $1.36 \%$ was obtained to $A_{1}$ as compared with the untreated bamboo specimens. However, an increment of $10.88 \%$ was generated with the further increase times of LbL self-assembly to five of A5 and over seven times than that of A1. It was also noted that WPG of B1 and B5 was 3.89 and $40.08 \%$, respectively. An obvious increase was generated compared to that of A1 (1.36\%) and A5 (10.88\%), indicating that the increment was caused by increasing concentration of PA-PEI solution. Therefore, it was concluded that adsorption capacities of PA and PEI were increased with the treatment by LbL self-assembly method and the increase of solution concentration.

\section{Fourier Transform Infrared Analysis}

FTIR curves of untreated and treated bamboo specimens are presented in Figure 3. PA5 and PA10 in Figure 3B are bamboo specimens treated with $5 \mathrm{wt} \%$ and $10 \mathrm{wt} \%$ of PA solutions, respectively. That of PEI5 and PEI10 are bamboo specimens treated with $5 \mathrm{wt} \%$ and $10 \mathrm{wt} \%$ of PEI solutions, respectively. An obvious decrease in the peak intensity at $3,440 \mathrm{~cm}^{-1}$ indicated the reduction of the content of free $-\mathrm{OH}$ in bamboo specimens after LbL self-assembly. Actually, PA was speedily assembled to the surface of bamboo specimens through physical absorption by hydrogen bond, indicating the excellent connection between PA and bamboo specimens (Guo et al., 2019). And then, PEI was also combined with PA by hydrogen bond during the immersion of bamboo specimens in PEI solutions. Hence, PEI was assembled to the surface of bamboo specimens with PA as intermediation. This is the reason why bamboo specimens were first dipped in PA solution and then PEI solution in our study. It was also noted that the band at approximately $1,633 \mathrm{~cm}^{-1}$ of $\mathrm{O}-\mathrm{P}-\mathrm{O}$ (Zhang et al., 2014a) and $\mathrm{P}=\mathrm{O}$ double bond stretching in the range of 1,200-1,260 $\mathrm{cm}^{-1}$ (Jiang et al., 2012) originated from PA clearly appear as illustrated in Figure 3. Combination between free - $\mathrm{OH}$ in bamboo specimens and $\mathrm{O}-\mathrm{P}-\mathrm{O}$ in $\mathrm{PA}$ was speedily formed with the immersing of bamboo specimens in PA solution, further leading a reduction in both the peak intensity of free -OH in bamboo specimens and O-P-O in PA. Besides, the band at $1,495 \mathrm{~cm}^{-1}$ was caused by symmetric and asymmetric bending vibration of $-\mathrm{NH}^{2}$ in PEI (Wang et al., 2014). The functional group of $-\mathrm{NH}^{2}$ in $\mathrm{PEI}$ was combined with $\mathrm{P}=\mathrm{O}$ in $\mathrm{PA}$ with the immersion of bamboo specimens in PA solution. The absorption peak at $1736 \mathrm{~cm}^{-1}$ corresponding to the $\mathrm{C}=\mathrm{O}$ stretching in the carboxyl (Duygu et al., 2008) of bamboo specimens was also observed. Cellulose was evidenced to exist in the bamboo specimens with the presence of the peak intensity at $1,056 \mathrm{~cm}^{-1}$ of C-O-C. A decrease in the peak intensity ratio between $\mathrm{C}-\mathrm{O}-\mathrm{C}$ and $\mathrm{O}-\mathrm{P}-\mathrm{O}$ indicated the depositing of PA on the surface of bamboo specimens. In summary, a thin film of PA-PEI was evidenced to be generated on the surface of treated bamboo specimens after LbL self-assembly with PA-PEI solution in this study.

\section{TG-DTA Analysis}

Figure 4 shows the TG and DTG curves of bamboo specimens before and after self-assembly with PA-PEI. The maximum weight loss rate $\left(\mathrm{WLR}_{\max }\right)$ and the temperature $(t)$ to $\mathrm{WLR}_{\max }$ of bamboo specimens before and after self-assembly with PA-PEI are listed in Table 2. The pyrolysis process of bamboo is mainly divided into three stages in accordance with the heat treatment temperature (Zhang Y. et al., 2020). An obvious weight loss was observed in bamboo specimens before and after self-assembly 

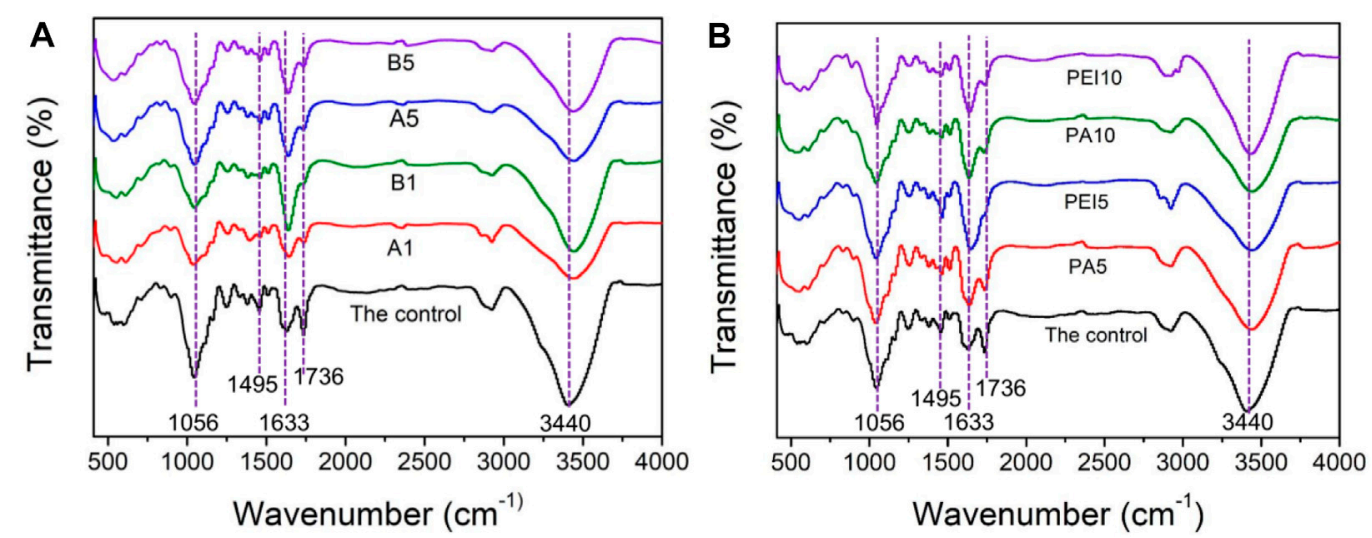

FIGURE 3 | FTIR curves of bamboo specimens: (A). bamboo specimens before and after self-assembly with PA-PEl; (B). bamboo specimens before and after treatment with PA solution and PEI solution.
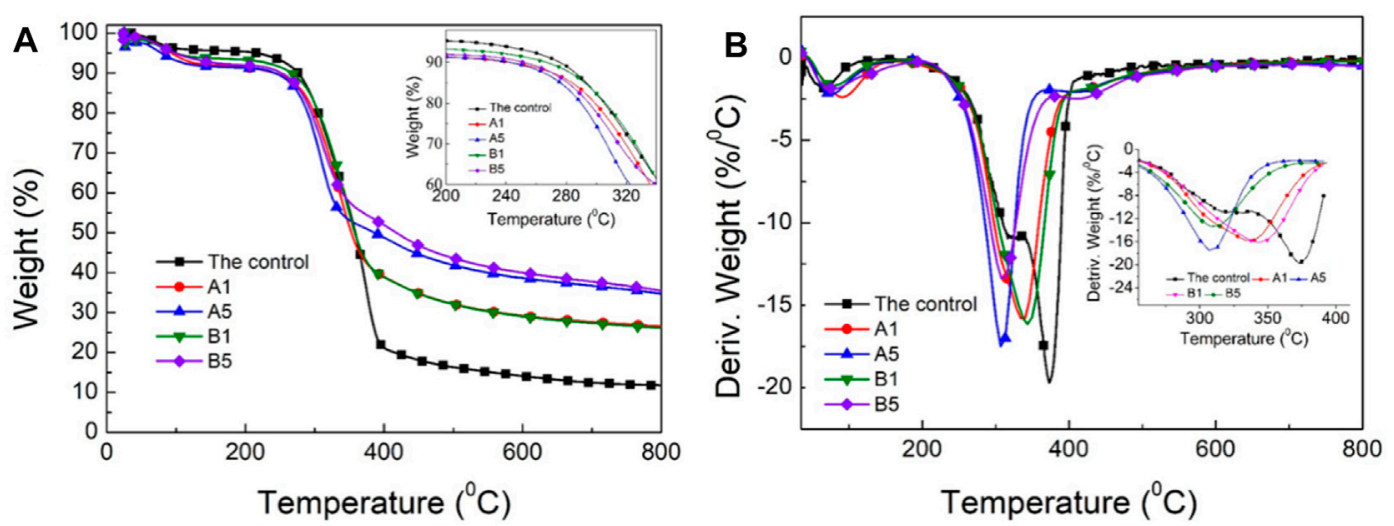

FIGURE 4 | Weight curves (A) and DTG curves (B) of bamboo specimens before and after self-assembly with PA-PEl in $\mathrm{N}_{2}$ atmosphere.

TABLE $2 \mid$ WLR $R_{\max }$ and $t$ of bamboo specimens in the pyrolysis process.

\begin{tabular}{|c|c|c|c|c|c|}
\hline Sample no. & $\begin{array}{c}1^{\text {st }} \text { WLR }_{\max } \\
\left(\% /{ }^{\circ} \mathrm{C}\right)\end{array}$ & $t_{1}\left({ }^{\circ} \mathrm{C}\right)$ & $\begin{array}{c}2^{\text {nd }} W^{\prime} R_{\max } \\
\left(\% /{ }^{\circ} \mathrm{C}\right)\end{array}$ & $\mathrm{t}_{2}\left({ }^{\circ} \mathrm{C}\right)$ & $\begin{array}{c}\text { Residual mass } \\
\text { at } 800^{\circ} \mathrm{C} \\
(\%)\end{array}$ \\
\hline $\mathrm{A} 1$ & 8.22 & 91.10 & 15.77 & 333.88 & 26.55 \\
\hline A5 & 8.67 & 75.89 & 17.49 & 306.81 & 34.76 \\
\hline B1 & 6.37 & 80.36 & 16.14 & 343.46 & 26.17 \\
\hline B5 & 7.88 & 80.34 & 13.35 & 307.9 & 35.51 \\
\hline
\end{tabular}

with PA-PEI in the temperature ranging from 80 to $90^{\circ} \mathrm{C}$ in the first stage of the pyrolysis process as shown in Figure $4 \mathbf{B}$. Compared with $\mathrm{WLR}_{\max }$ of the control group $\left(4.4 \% /{ }^{\circ} \mathrm{C}\right)$, the $\mathrm{WLR}_{\text {max }}$ of treated bamboo specimens was obviously increased by $86.8 \%$ (A1) and $95.9 \%$ (B1), respectively. However, the corresponding increment of $\mathrm{WLR}_{\max }$ was $44.8 \%$ (A5) and $79.1 \%$ (B5) with the further increase times of self-assembly to five. Besides, $t$ of the treated bamboo specimens was also increased by $36.1 \%$ (A1), $13.4 \%$ (B1), 20.1\% (A5), and
$20.0 \%$ (B5), respectively. This may be due to the evaporation of moisture in bamboo specimens in accordance with the pyrolysis process of bamboo and wood (Duygu et al., 2008; Poletto et al., 2012). Besides, overflow of trace free organic molecules for PA was also observed in the pyrolysis process of the treated bamboo specimens according to the boiling points of PA and PEI. A slight difference between bamboo specimens before and after self-assembly with PA-PEI was observed due to the evaporation of PA. 

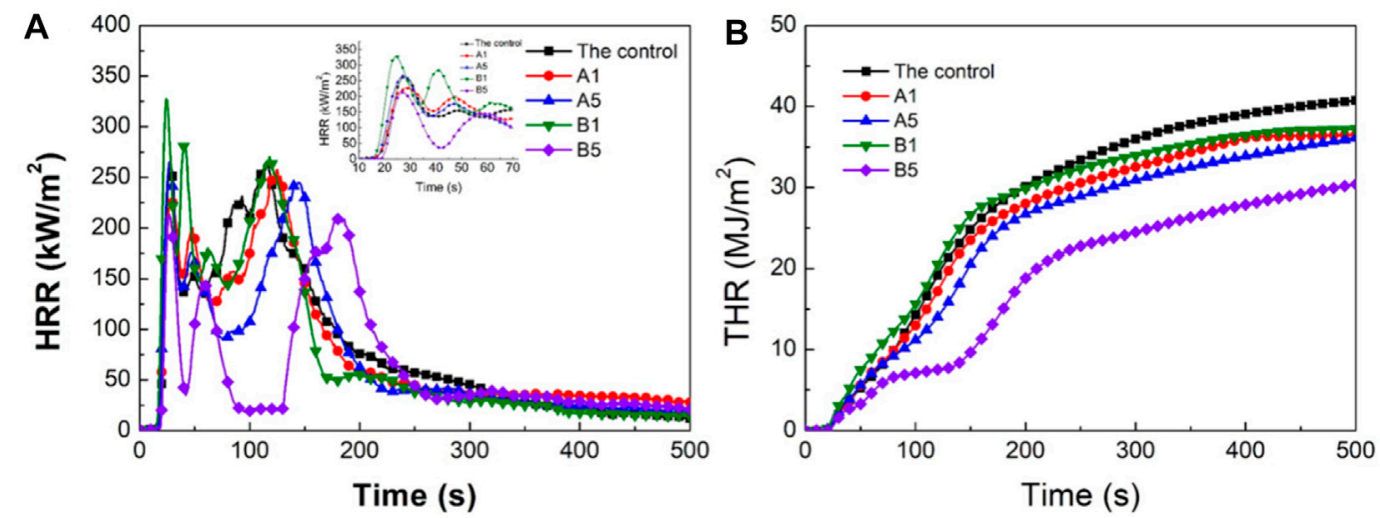

FIGURE 5 | HRR (A) and THR (B) curves of bamboo specimens before and after LbL self-assembly with PA-PEl.

As listed in Table 2, $\mathrm{WLR}_{\max }$ of the treated bamboo specimens in the second stage of the pyrolysis process was decreased by $19.91 \%$ (A1), $11.17 \%$ (A5), $18.03 \%$ (B1), and $32.20 \%$ (B5) in comparison with that of the control group $\left(19.69 \% /{ }^{\circ} \mathrm{C}\right)$, respectively. Moreover, $t$ of $\mathrm{A} 1\left(333.88^{\circ} \mathrm{C}\right)$ and $\mathrm{B} 1\left(343.46^{\circ} \mathrm{C}\right)$ were slightly decreased by 10.52 and $7.95 \%$, respectively. The decrements of $t$ were increased to $17.77 \%$ (A5) and $17.48 \%$ (B5) with the further increase time for LbL self-assembly with PA-PEI to five. In addition, it was found that residual mass at $800{ }^{\circ} \mathrm{C}$ was significantly increased to $126.34 \%$ (A1) and $123.10 \%$ (B1) after the first time of LbL self-assembly with PA-PEI. A significant increase in residual mass was generated with the increase of times for LbL self-assembly with PA-PEI to five, which was nearly doubled (i.e., A5: 196.33\% and B5: 202.73\%). This may be due to the PA-PEI thin film formed on the surface of treated bamboo specimens in the LbL assembly process with PA-PEI solutions. The thin film was thick enough to prevent bamboo specimens from thermal decomposition with the increase of concentration of PA-PEI solution and times of LbL self-assembly. Hence, a remarkable increase was found in the residual mass at $800^{\circ} \mathrm{C}$ of treated bamboo specimens (Shen et al., 2016).

It has been reported that the peak at $320 \sim 330^{\circ} \mathrm{C}$ and $373^{\circ} \mathrm{C}$ of bamboo material under $\mathrm{N}_{2}$ atmosphere is the degradation of hemicellulose and lignin, respectively (Brebu and Vasile, 2010; Herrera et al., 2014). Additionally, incombustible gases, such as $\mathrm{N}_{2}$, are always generated in the decomposition process of PEI in the phosphorus-nitrogen flame retardant system (PA-PEI) formed on the surface of bamboo specimens after LbL selfassembly with PA-PEI and a relatively weak contribution to the TG-DTG curve in this study. The decomposition of PA was generated in a low-temperature stage, and metaphosphoric acid was formed in this stage with PA as an acid source. Besides, binding interaction between metaphosphoric acid and the matrix occurred and further resulted in the formation of a dehydration carbon layer. Moreover, the degradation chain reaction of the matrix shifts to the formation of the carbon layer and leads to the increase in the carbon residue contents (Jeng et al., 2002; Daneluti and Matos, 2013; Cheng et al., 2016b). Therefore, the maximum degradation rate of the substrate comes earlier at a lower temperature. The same conclusion was also obtained by increasing residual mass, as shown in Figure 4A, Table 2, and the attenuation of the second peak in DTG curves illustrated in Figure 4B. It was also noted that times of LbL self-assembly with PA-PEI makes a great difference to pyrolysis process of bamboo specimens. For the bamboo specimens LbL self-assembly with PAPEI, the following order of residual mass was found: B5 $>A 5>B 1>A 1$. Hence, the bamboo specimens LbL self-assembly with PA-PEI five times (A5 and B5) showed the highest residual mass.

\section{Cone Calorimeter Analysis}

\section{Heat Release Rate and Total Heat Release}

HRR (A) and THR (B) curves of bamboo specimens before and after self-assembly with PA-PEI are presented in Figure 5. As illustrated in Figure 5A, the combustion process of bamboo specimens is mainly divided into two stages. For the first stage, two HRR peaks of the untreated and treated bamboo specimens were observed. Peak HRR (PHRR) of A5 and B1 was greater than that of the control. And the time to PHRR of A5 and B1 was also slightly decreased, indicating the earlier combustion of A5 and B1. This may be due to the dehydration of wood components catalyzed by PA in a low-temperature stage, and the degradation of organic compounds was accelerated, which promoted the release of combustible volatile products (Wang et al., 2004; Gong et al., 2020). Moreover, PHRR of B5 $\left(213.41 \mathrm{~kW} / \mathrm{m}^{2}\right)$ was decreased by $18.71 \%$ as compared with the control group $\left(262.54 \mathrm{~kW} / \mathrm{m}^{2}\right)$. Therefore, it is evident that increasing the concentration of PA-PEI solutions and times of LbL self-assembly with PA-PEI contributes to a slight improvement in the flame retardancy of bamboo specimens in the first combustion stage of cone calorimeter analysis. This may be due to the PA-PEI thin film generated on the surface of treated bamboo specimens in the LbL assembly process with PA-PEI solutions. The PA-PEI thin film can effectively prevent bamboo specimens from combusting with the increase of concentration of PA-PEI solution and times of LbL assembly.

The PHRR in the second stage, average HRR (AHRR), PHRR, and THR of bamboo specimens are shown in Table 3. A reduction in PHRR of bamboo specimens after LbL self- 
TABLE 3 | AHRR and PHRR of bamboo specimens before and after LbL self-assembly with PA-PEI.

\begin{tabular}{|c|c|c|c|c|c|}
\hline Sample no. & AHRR $\left(\mathrm{kW} / \mathrm{m}^{2}\right)$ & $\mathrm{PHRR}_{2}\left(\mathrm{~kW} / \mathrm{m}^{2}\right)$ & $\begin{array}{c}\text { Time to } \\
\text { PHRR }_{2} \text { (s) }\end{array}$ & PHRR $\left(\mathrm{kW} / \mathrm{m}^{2}\right)$ & THR $\left(\mathrm{MJ} / \mathrm{m}^{2}\right)$ \\
\hline The control & 76.34 & 264.63 & 115 & 264.63 & 41.67 \\
\hline A1 & 83.30 & 257.55 & 125 & 257.55 & 39.24 \\
\hline A5 & 64.34 & 245.00 & 144 & 265.15 & 38.02 \\
\hline B1 & 62.40 & 276.12 & 118 & 327.25 & 37.21 \\
\hline B5 & 53.68 & 212.84 & 181 & 213.41 & 32.38 \\
\hline
\end{tabular}

assembly with PA-PEI was generated as compared to the control. The corresponding values of $\mathrm{PHRR}_{2}$ were decreased by $2.68 \%$ (A1), $11.17 \%$ (A5), and $19.57 \%$ (B5) in comparison with the control group, respectively. The time to PHRR was delayed from $115 \mathrm{~s}$ (the control group) to $125 \mathrm{~s}$ (A1), $144 \mathrm{~s}$ (A5), $118 \mathrm{~s}$ (B1), and $181 \mathrm{~s}$ (B5), suggesting lower flammability of the treated bamboo specimens. The reason was that the increasing concentrations of PA-PEI solution and times of LbL selfassembly with PA-PEI resulted in the generation of IFR film on the surface of bamboo specimens, which can protect the underlying bamboo matrix from sharp combustion during the cone calorimeter test. However, PHRR of B5 $\left(213.41 \mathrm{~kW} / \mathrm{m}^{2}\right)$ prepared by using the IFR system with $10 \mathrm{wt} \% \mathrm{PA}$ solution and $10 \mathrm{wt} \%$ PEI solution was greater than that of FR wood $\left(164.80 \mathrm{~kW} / \mathrm{m}^{2}\right)$ prepared by using $8 \mathrm{wt} \% \mathrm{PA}$ solution and $3 \mathrm{wt} \%$ uracil solution (Zhang L. et al., 2020).

THR curves of bamboo specimens before and after LbL selfassembly with PA-PEI are presented in Figure 5B. It was noted that the THR of the treated bamboo specimens was decreased with the increase in the concentration of PA-PEI solution and times of LbL self-assembly. For the bamboo specimens LbL selfassembly with PA-PEI, the following order of THR was found: $\mathrm{A} 1>\mathrm{A} 5>\mathrm{B} 1>\mathrm{B} 5$ (Table 3). A small decrement of $8.76 \%$ (from $41.67 \mathrm{MJ} / \mathrm{m}^{2}$ to $38.02 \mathrm{MJ} / \mathrm{m}^{2}$ ) occurred in the THR of bamboo specimens (A5) self-assembly with the IFR system with $5 \mathrm{wt} \%$ PA solution and $5 \mathrm{wt} \%$ PEI solution with increase times of LbL selfassembly to five in comparison with the control. Moreover, THR of bamboo specimens (B5) self-assembly with the IFR system with $10 \mathrm{wt} \% \mathrm{PA}$ solution and $10 \mathrm{wt} \%$ PEI solution five times the LbL self-assembly reduced by $22.30 \%$ (from $41.67 \mathrm{MJ} / \mathrm{m}^{2}$ to $32.38 \mathrm{MJ} / \mathrm{m}^{2}$ ). It indicated that both improvement in PA-PEI solution and times of LbL self-assembly can help to improve the flame retardancy of bamboo specimens. It was also noted that THR of B5 $\left(32.38 \mathrm{MJ} / \mathrm{m}^{2}\right)$ prepared by using the IFR system with $10 \mathrm{wt} \%$ PA solution and $10 \mathrm{wt} \%$ PEI solution was greater than that of FR wood $\left(16.90 \mathrm{MJ} / \mathrm{m}^{2}\right)$ prepared by using $8 \mathrm{wt} \%$ PA solution and $3 \mathrm{wt} \%$ uracil solution (Zhang Y. et al., 2020).

\section{Time to Ignition and Fire Performance Index}

Time to ignition (TTI) is the continuous ignition time required from the surface of the tested materials to be ignited under the preset heat radiation power. Fire performance index (FPI) is the ratio of the TTI of the tested material to the PHRR. FPI is calculated according to the following formula: FPI $\left(\mathrm{s} /\left(\mathrm{kW} \cdot \mathrm{m}^{-2}\right)\right)=$ TTI/PHRR, which is usually used to evaluate the potential flashover hazard of the material in a fire (Petrella, 1994; Xu et al., 2013; Yu

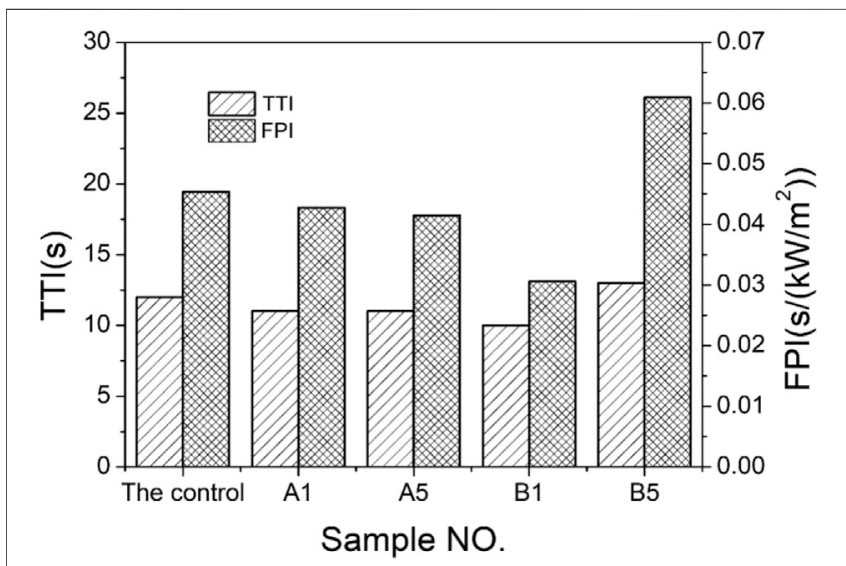

FIGURE 6 | TTI and FPI of bamboo specimens before and after LbL selfassembly with PA-PEl.

et al., 2016; Hou et al., 2017). Besides, the flashover time of the tested material is an important basis for the design of fire escape time. The larger the FPI, the later the material flashover time.

Figure 6 plots TTI and FPI of bamboo specimens before and after LbL self-assembly with PA-PEI. It indicated that the concentration of PA-PEI solution and times of LbL self-assembly had a limited effect on TTI of bamboo specimens. Additionally, TTI of bamboo specimens was slightly increased from 12 to $13 \mathrm{~s}$ with the increasing times of LbL self-assembly to five, with the IFR system with $10 \mathrm{wt} \%$ PA solution and $10 \mathrm{wt} \%$ PEI solution. However, FPI of B5 was increased by $35.56 \%$ (from $0.045 \mathrm{~s} /\left(\mathrm{kW} / \mathrm{m}^{2}\right.$ ) to $0.061 \mathrm{~s} /$ $\left.\left(\mathrm{kW} / \mathrm{m}^{2}\right)\right)$ in comparison to the control. Actually, both increase in TTI and decrease in PHRR contribute to the increase of FPI, further leading to improved fire resistance of bamboo specimens LbL selfassembly with PA-PEI (Hou et al., 2019).

\section{Mass Loss Rate and Residual Mass}

MLR in initial $360 \mathrm{~s}$ and residual mass of bamboo specimens before and after LbL self-assembly with PA-PEI are presented in Figure 7. As shown in Figure 7A, MLR of the treated bamboo specimens was decreased with the increase in PA-PEI solution and times for LbL self-assembly with PA-PEI. For the bamboo specimens LbL self-assembly with PA-PEI, the following order of MLR in initial $180 \mathrm{~s}$ was found: $\mathrm{B} 1>\mathrm{A} 1>\mathrm{A} 5>\mathrm{B} 5$. That of MLR of $\mathrm{A} 1, \mathrm{~A} 5$, and $\mathrm{B} 1$ was almost the same from 180 to $360 \mathrm{~s}$ as presented in Figure 7A. Residual mass of A1 (1.54\%) and B1 $(1.07 \%)$ decreased more considerably than that of the control 

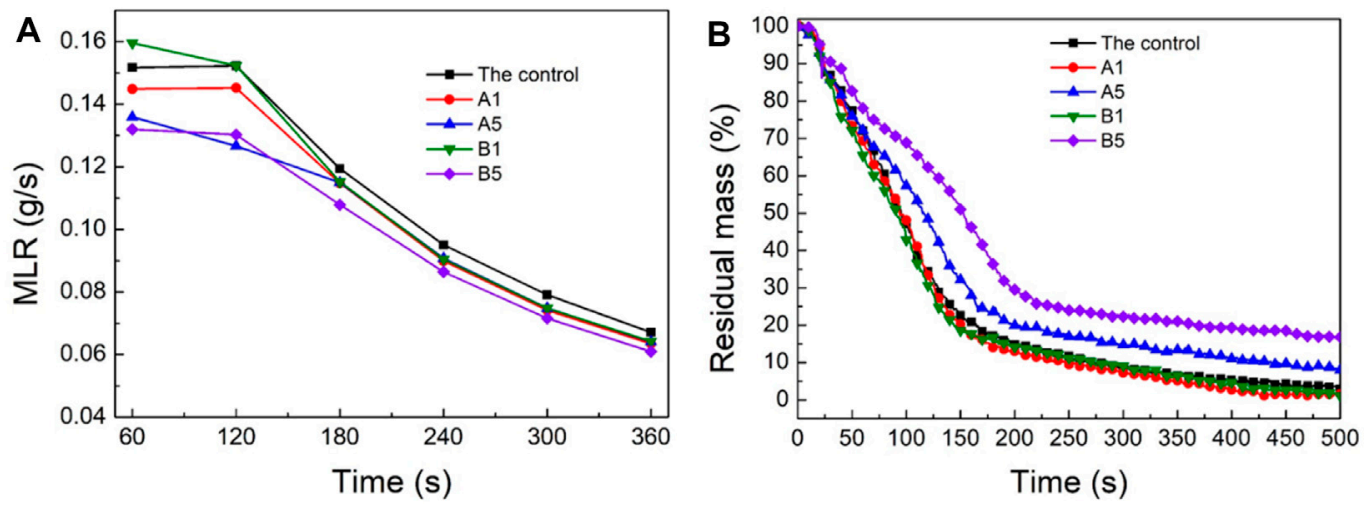

FIGURE 7 | MLR (A) in initial $360 \mathrm{~s}$ and residual mass (B) of bamboo specimens before and after LbL self-assembly with PA-PEI.

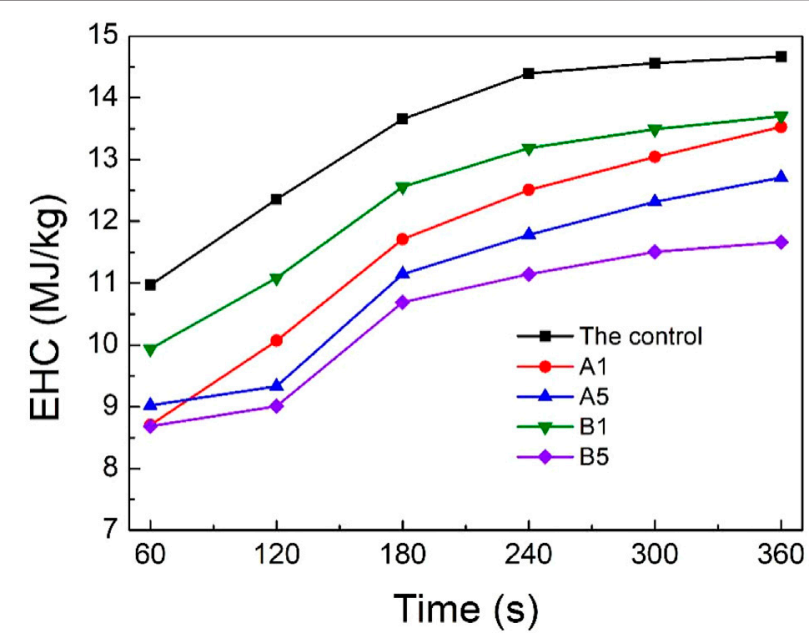

FIGURE 8 | EHC of bamboo specimens before and after LbL selfassembly with PA-PEl in initial $360 \mathrm{~s}$.

group (2.90\%) as illustrated in Figure 7B. Besides, residual mass of A5 (8.07\%) was $178.28 \%$ greater and B5 (16.84\%) was $480.69 \%$ greater than the control group (2.90\%), respectively. It indicated that the IFR system with PA-PEI solution can exert a flame retardant action at the flaming combustion stage to fix the carbon source, thereby producing more carbon residue (i.e., Residual mass). Additionally, the PA-PEI thin film formed on the surface of the treated bamboo specimens in LbL assembly process can effectively protect bamboo specimens from combusting with increasing times of LbL self-assembly. Similar results were obtained from TG and DTG analysis, as shown in Figure 4.

Effective Heat of Combustion, $\mathrm{CO}$ Yield, and $\mathrm{CO}_{2}$ Yield Figure 8 illustrates the EHC of bamboo specimens before and after LbL self-assembly with PA-PEI in initial $360 \mathrm{~s}$, and the detailed data for the EHC of the bamboo specimens before and after LbL self-assembly with PA-PEI are listed in Table 4. As shown in Figure 8, the EHC of the treated bamboo specimens was decreased with increasing PA-PEI concentrations and times of LbL self-assembly. Average EHC and peak EHC of bamboo specimens after LbL self-assembly with PA-PEI (i.e., A1, A5, and B1) were slightly decreased by less than $10 \%$ as shown in Table 4 . Besides, average EHC and peak EHC of bamboo specimens after LbL self-assembly with PA-PEI were decreased by $18.90 \%$ (B5: $11.84 \mathrm{MJ} / \mathrm{kg}$ ) with increasing times of LbL self-assembly to five at the IFR system with $10 \mathrm{wt}$ $\%$ PA solution and $10 \mathrm{wt} \%$ PEI solution in comparison with the control group $(14.60 \mathrm{MJ} / \mathrm{kg})$. In addition, the time to peak EHC of the treated bamboo specimens was remarkably prolonged and more than doubled to compare with the control group (Table 4), indicating that the IFR system with $10 \mathrm{wt} \%$ PA solution and $10 \mathrm{wt} \%$ PEI solution plays a significant role in limiting the production of flammable volatile products.

$\mathrm{COY}$ and $\mathrm{CO}_{2} \mathrm{Y}$ of bamboo specimens before and after selfassembly with PA-PEI in the initial $360 \mathrm{~s}$ are presented in Figure 9. It was found that the COY was increased with the increase in the concentration of PA-PEI solution and the times of LbL self-assembly with PA-PEI, and the following order of COY in the initial $360 \mathrm{~s}$ was found: $\mathrm{B} 5>\mathrm{A} 5>\mathrm{B} 1>\mathrm{A} 1$. The reason was that the thin film of PA-PEI formed on the surface of the treated bamboo specimens was thick enough to prevent bamboo specimens from combusting with the increase of concentration of PA-PEI solution and times of LbL selfassembly (Jiang et al., 2012). Hence, a remarkable increase in the COY of the treated bamboo specimens was obtained and increased with the delay of combustion time. However, the following order of $\mathrm{CO}_{2} \mathrm{Y}$ in the initial $360 \mathrm{~s}$ was found: $\mathrm{B} 1>\mathrm{A} 1>\mathrm{B} 5>\mathrm{A} 5$. The incomplete combustion of the treated bamboo specimens led to a reduction in the $\mathrm{CO}_{2} \mathrm{Y}$ during the cone calorimeter test.

Average $\mathrm{COY}$ and $\mathrm{CO}_{2} \mathrm{Y}$ of bamboo specimens before and after self-assembly with PA-PEI are shown in Figure 10. The average COY of the treated bamboo specimens was increased with the increase in the times of LbL self-assembly with PA-PEI, and the following order of average COY was found: $\mathrm{B} 5>\mathrm{A} 5>\mathrm{A} 1>\mathrm{B} 1$. The average $\mathrm{COY}$ of the treated bamboo specimens was decreased by $50.28 \%$ (A1), $72.02 \%$ (B1), $21.93 \%$ (A5), and $17.77 \%$ (B5) as compared with the control, 
TABLE 4 | EHC of bamboo specimens before and after LbL self-assembly with PA-PEl in initial $360 \mathrm{~s}$.

\begin{tabular}{|c|c|c|c|}
\hline Sample no. & Average EHC/(MJ/kg) & Peak EHC/(MJ/kg) & Time to peak EHC/s \\
\hline The control & 14.60 & 74.41 & 115 \\
\hline A1 & 14.45 & 79.78 & 324 \\
\hline A5 & 13.54 & 69.46 & 551 \\
\hline B1 & 13.35 & 78.82 & 359 \\
\hline B5 & 11.84 & 69.94 & 151 \\
\hline
\end{tabular}
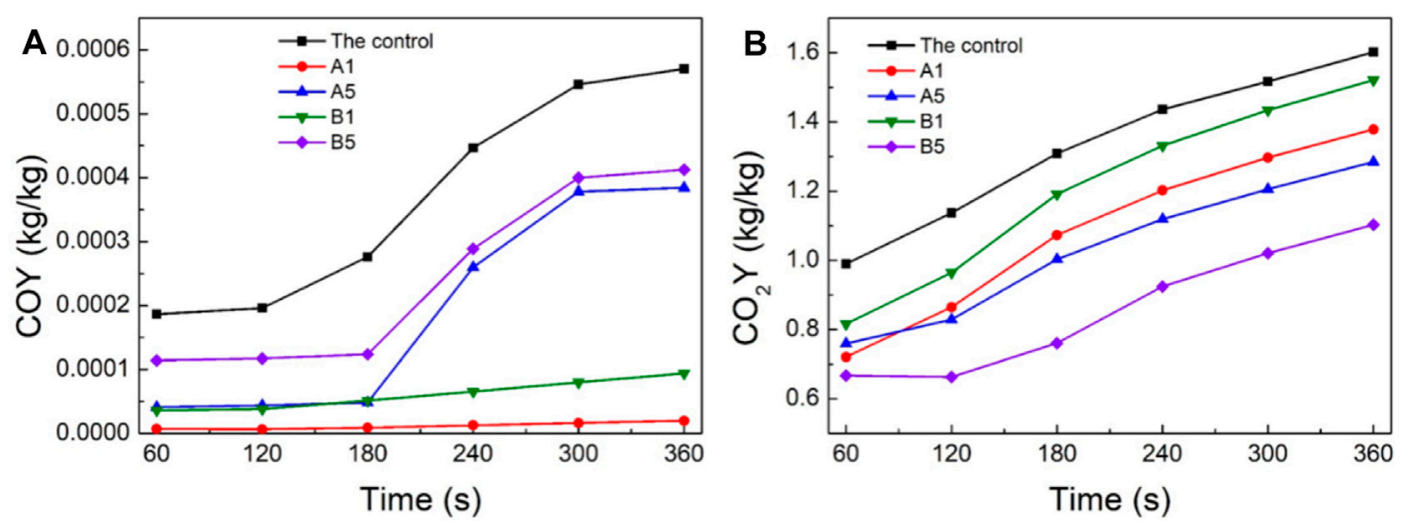

FIGURE 9 | COY (A) and $\mathrm{CO}_{2} \mathrm{Y}$ (B) of bamboo specimens before and after LbL self-assembly with PA-PEI in initial $360 \mathrm{~s}$.

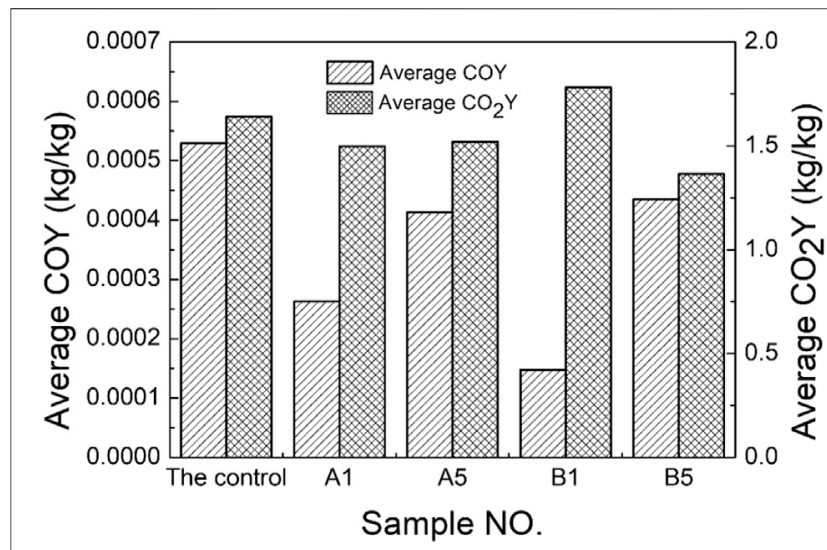

FIGURE 10| Average $\mathrm{COY}$ and $\mathrm{CO}_{2} \mathrm{Y}$ of bamboo specimens before and after LbL self-assembly with PA-PEl.

respectively. By contrast, the average $\mathrm{CO}_{2} \mathrm{Y}$ of bamboo specimens after self-assembly with PA-PEI (i.e., A1, A5, and B5) was slightly decreased by less than $20 \%$. B5 showed a decrease of $16.88 \%$ in average $\mathrm{CO}_{2} \mathrm{Y}$ (B5: $1.364 \mathrm{~kg} / \mathrm{kg}$ ) compared to the control group $(1.641 \mathrm{~kg} / \mathrm{kg})$. It indicated that the IFR system with PA-PEI played an obvious inhibiting effect on the combustion of bamboo materials during the cone calorimeter test (Nguyen et al., 2013). It is well known that bamboo is mainly composed of cellulose, lignin, and hemicellulose, and it will crack to produce smallmolecule combustible substances under combustion conditions. Thereby, $\mathrm{CO}$ and $\mathrm{CO}_{2}$ are expected to be generated after the combustion of bamboo (Jakab et al., 1995; Bassilakis et al., 2001). Both increase in average COY and decrease in $\mathrm{CO}_{2} \mathrm{Y}$ of the treated bamboo specimens were caused by the imperfect combustion of bamboo specimens LbL self-assembly with PA-PEI. The thin film of PA-PEI formed on the surface of the treated bamboo specimens was thick enough to prevent bamboo specimens from combusting with the increase of concentration of PA-PEI solution and times of LbL self-assembly (Nguyen et al., 2013).

Combined with the analysis of EHC shown in Figure 8 and Table 4, an obvious fixation effect of the IFR system with PA-PEI solution on the $\mathrm{C}$ element was obtained in the combustion process of bamboo materials. Additionally, the PA-PEI thin film formed on the surface of treated bamboo specimens in the LbL assembly process was thick enough to protect bamboo specimens from thermal decomposition and sharp combustion, leading to the increase in amount of residual mass (Figure 7B) and decrease in EHC (Figure 8) during the cone calorimeter test. Similar results were obtained from the TG-DTG analysis of bamboo specimens after self-assembly with PA-PEI. The formation of a protective char layer during the cone calorimeter measurement acts as a barrier, reduces the HRR and the yield of $\mathrm{CO}_{2}$, and further increases residual mass, indicating that a well-integrated flame retardant performance was obtained to the bamboo specimens treated with the IFR solution of $10 \mathrm{wt} \% \mathrm{PA}$ and 10 wt $\%$ PEI five times the LbL self-assembly with PA-PEI.

\section{CONCLUSIONS}

The PA-PEI-based fire-retardant layer was coated on the surface of shaving super bamboo specimens by an LbL self-assembly 
technology to improve the flame retardancy of bamboo materials in this study. The effects of PA-PEI solution and times of LbL selfassembly with PA-PEI on the flame retardancy of bamboo specimens were systematically investigated. The LbL selfassembly with PA-PEI promoted the generation of a residual char layer with excellent stability. In addition, a higher solution concentration of PA-PEI and more times of LbL self-assembly made the specimens exhibit smaller HRR and lower yield of $\mathrm{CO}$ and $\mathrm{CO}_{2}$, but greater residual mass and FPI values. For bamboo specimens self-assembly with $10 \mathrm{wt} \%$ PA solution and $10 \mathrm{wt} \%$ PEI solution five times, PHRR and THR were reduced by 19.36 and $22.30 \%$, respectively, compared to the control group. In addition, the FPI and residual mass of the bamboo specimens self-assembly with $10 \mathrm{wt} \%$ PA solution and $10 \mathrm{wt} \%$ PEI solution 5 times were increased by 35.56 and $480.70 \%$ in comparison with the control group, respectively. This work contributes to a better understanding of the effects of LbL self-assembly with PA-PEI on the flame retardancy of bamboo specimens, thus providing a useful approach for the value-added utilization of bamboo materials.

\section{REFERENCES}

Bassilakis, R., Carangelo, R., and Wójtowicz, M. (2001). TG-FTIR Analysis of Biomass Pyrolysis. Fuel 80 (4), 1765-1786. doi:10.1016/S0016-2361(01) 00061-8

Brebu, M., and Vasile, C. (2010). Thermal Degradation of Lignin-A Review. Cell. Chem. Technol. 44 (9), 353-363. doi:10.1007/s10086-010-1118-1

Cheng, X.-W., Guan, J.-P., Tang, R.-C., and Liu, K.-Q. (2016a). Phytic Acid as a Bio-Based Phosphorus Flame Retardant for Poly(lactic Acid) Nonwoven Fabric. J. Clean. Prod. 124, 114-119. doi:10.1016/j.jclepro.2016.02.113

Cheng, X.-W., Guan, J.-P., Chen, G., Yang, X.-H., and Tang, R.-C. (2016b). Adsorption and Flame Retardant Properties of Bio-Based Phytic Acid on Wool Fabric. Polymers 8 (4), 122. doi:10.3390/polym8040122

Cheng, X.-W., Guan, J.-P., Kiekens, P., Yang, X.-H., and Tang, R.-C. (2019). Preparation and Evaluation of an Eco-Friendly, Reactive, and Phytic AcidBased Flame Retardant for Wool. Reactive Funct. Polym. 134, 58-66. doi:10.1016/j.reactfunctpolym.2018.11.006

Daneluti, A. L. M., and Matos, J. d. R. (2013). Study of thermal Behavior of Phytic Acid. Braz. J. Pharm. Sci. 49, 275-283. doi:10.1590/S1984-82502013000200009

Dusková, D., Marounek, M., and Brezina, P. (2001). Determination of Phytic Acid in Feeds and Faeces of Pigs and Poultry by Capillary Isotachophoresis. J. Sci. Food Agr. 81 (1), 36-41. doi:10.1002/1097-0010(20010101)81:13.0.CO;2-A

Duygu, K., Sandor, P., and Yaman, B. (2008). Effect of thermal Treatment on the Chemical Composition and Mechanical Properties of Birch and aspen. Bioresources 3 (2), 517-537. doi:10.1016/S0016-7037(00)00094-2

Fang, F., Ran, S., Fang, Z., Song, P., and Wang, H. (2019). Improved Flame Resistance and Thermo-Mechanical Properties of Epoxy Resin Nanocomposites from Functionalized Graphene Oxide via Self-Assembly in Water. Compos. B. Eng. 165, 406-416. doi:10.1016/j.compositesb.2019.01.086

Fang, F., Song, P., Ran, S., Guo, Z., Wang, H., and Fang, Z. (2018). A Facile Way to Prepare Phosphorus-Nitrogen-Functionalized Graphene Oxide for Enhancing the Flame Retardancy of Epoxy Resin. Composites Commun. 10, 97-102. doi:10.1016/j.coco.2018.08.001

Gong, W., Fan, M., Luo, J., Liang, J., and Meng, X. (2020). Effect of Nickel Phytate on Flame Retardancy of Intumescent Flame Retardant Polylactic Acid. Polym. Adv. Technol. 32 (4), 1548-1559. doi:10.1002/pat.5190

Guo, W., Kalali, E. N., Wang, X., Xing, W., Zhang, P., Song, L., et al. (2019). Processing Bulk Natural Bamboo into a strong and Flame-Retardant Composite Material. Ind. Crops Prod. 138, 111478. doi:10.1016/ j.indcrop.2019.111478

\section{DATA AVAILABILITY STATEMENT}

The original contribution presented in the study are included in the article/supplementary material; further inquiries can be directed to the corresponding authors.

\section{AUTHOR CONTRIBUTIONS}

$\mathrm{PL}, \mathrm{YJ}$, and $\mathrm{JH}$ executed the experiment and wrote the manuscript. YY conceived and designed the study and experiment plan. LM and WC revised the manuscript. XR and $\mathrm{XZ}$ analyzed the experimental results.

\section{FUNDING}

The work was financially supported by the National Natural Science Foundation of China (Grant No. 31800473) and the Natural Science Foundation of Zhejiang province (Grant No. LY17C160007).

He, W., Song, P., Yu, B., Fang, Z., and Wang, H. (2020). Flame Retardant Polymeric Nanocomposites through the Combination of Nanomaterials and Conventional Flame Retardants. Prog. Mater. Sci. 114, 100687. doi:10.1016/ j.pmatsci.2020.100687

Herrera, R., Erdocia, X., Llano-Ponte, R., and Labidi, J. (2014). Characterization of Hydrothermally Treated wood in Relation to Changes on its Chemical Composition and Physical Properties. J. Anal. Appl. Pyrolysis 107, 256-266. doi:10.1016/j.jaap.2014.03.010

Hou, J., Cai, Z., and Lu, K. (2017). Cone Calorimeter Evaluation of Reinforced Hybrid wood-aluminum Composites. J. Fire Sci. 35 (2), 118-131. doi:10.1177/ 0734904116683717

Huo, S., Liu, Z., Li, C., Wang, X., Cai, H., and Wang, J. (2019). Synthesis of a Phosphaphenanthrene/benzimidazole-Based Curing Agent and its Application in Flame-Retardant Epoxy Resin. Polym. Degrad. Stab. 163, 100-109. doi:10.1016/j.polymdegradstab.2019.03.003

Huo, S., Song, P., Yu, B., Ran, S., Chevali, V. S., Liu, L., et al. (2021). Phosphoruscontaining Flame Retardant Epoxy Thermosets: Recent Advances and Future Perspectives. Prog. Polym. Sci. 114, 101366. doi:10.1016/ j.progpolymsci.2021.101366

Jakab, E., Faix, O., Till, F., and Székely, T. (1995). Thermogravimetry/mass Spectrometry Study of Six Lignins within the Scope of an International Round Robin Test. J. Anal. Appl. Pyrolysis 35 (2), 167-179. doi:10.1016/ 0165-2370(95)00907-7

Jeng, R.-J., Shau, S.-M., Lin, J.-J., Su, W.-C., and Chiu, Y.-S. (2002). Flame Retardant Epoxy Polymers Based on All Phosphorus-Containing Components. Eur. Polym. J. 38 (4), 683-693. doi:10.1016/S0014-3057(01) 00246-4

Jiang, G., Qiao, J., and Hong, F. (2012). Application of Phosphoric Acid and Phytic Acid-Doped Bacterial Cellulose as Novel Proton-Conducting Membranes to PEMFC. Int. J. Hydrogen Energ. 37 (11), 9182-9192. doi:10.1016/ j.ijhydene.2012.02.195

Jin, X., Gu, X., Chen, C., Tang, W., Li, H., Liu, X., et al. (2017). The Fire Performance of Polylactic Acid Containing a Novel Intumescent Flame Retardant and Intercalated Layered Double Hydroxides. J. Mater. Sci. 52 (20), 12235-12250. doi:10.1007/s10853-017-1354-5

Jo, S., Jeong, H., Bae, S. R., and Jeon, S. (2008). Modified Platinum Electrode with Phytic Acid and Single-Walled Carbon Nanotube: Application to the Selective Determination of Dopamine in the Presence of Ascorbic and Uric Acids. Microchem. J. 88 (1), 1-6. doi:10.1016/j.microc.2007.08.005

Laachachi, A., Ball, V., Apaydin, K., Toniazzo, V., and Ruch, D. (2011). Diffusion of Polyphosphates into (Poly(allylamine)-montmorillonite) Multilayer Films: 
Flame Retardant-Intumescent Films with Improved Oxygen Barrier. Langmuir 27 (22), 13879-13887. doi:10.1021/la203252q

Laufer, G., Kirkland, C., Morgan, A. B., and Grunlan, J. C. (2012). Intumescent Multilayer Nanocoating, Made with Renewable Polyelectrolytes, for FlameRetardant Cotton. Biomacromolecules 13 (9), 2843-2848. doi:10.1021/ bm300873b

Liu, C., Zhang, T., Luo, Y., Wang, Y., Li, J., Ye, T., et al. (2021). Multifunctional Polyurethane Sponge Coatings with Excellent Flame Retardant, Antibacterial, Compressible, and Recyclable Properties. Compos. B. Eng. 215, 108785. doi:10.1016/j.compositesb.2021.108785

Liu, L., Huang, G., Song, P., Yu, Y., and Fu, S. (2016). Converting Industrial Alkali Lignin to Biobased Functional Additives for Improving Fire Behavior and Smoke Suppression of Polybutylene Succinate. ACS Sustain. Chem. Eng. 4 (9), 4732-4742. doi:10.1021/acssuschemeng.6b00955

Nguyen, T.-M., Chang, S., Condon, B., Slopek, R., Graves, E., and Yoshioka-Tarver, M. (2013). Structural Effect of Phosphoramidate Derivatives on the thermal and Flame Retardant Behaviors of Treated Cotton Cellulose. Ind. Eng. Chem. Res. 52 (13), 4715-4724. doi:10.1021/ie400180f

Petrella, R. V. (1994). The Assessment of Full-Scale Fire Hazards from Cone Calorimeter Data. J. Fire Sci. 12 (1), 14-43. doi:10.1177/073490419401200102

Poletto, M., Zattera, A. J., Forte, M. M. C., and Santana, R. M. C. (2012). Thermal Decomposition of wood: Influence of wood Components and Cellulose Crystallite Size. Bioresour. Techn. 109, 148-153. doi:10.1016/ j.biortech.2011.11.122

Pope, I., Hidalgo, J. P., Osorio, A., Maluk, C., and Torero, J. L. (2019). Thermal Behaviour of Laminated Bamboo Structures under Fire Conditions. Fire Mater. 45 (3), 321-330. doi:10.1002/fam.2791

Ran, S., Fang, F., Guo, Z., Song, P., Cai, Y., Fang, Z., et al. (2019). Synthesis of Decorated Graphene with P, N-Containing Compounds and its Flame Retardancy and Smoke Suppression Effects on Polylactic Acid. Compos. B. Eng. 170, 41-50. doi:10.1016/j.compositesb.2019.04.037

Scurlock, J. M. O., Dayton, D. C., and Hames, B. (2000). Bamboo: an Overlooked Biomass Resource? Biomass Bioenergy 19 (4), 229-244. doi:10.1016/S09619534(00)00038-6

Shen, Y., Gong, W., Zheng, B., Meng, X., and Gao, L. (2016). Synergistic Effect of $\mathrm{Ni}$-Based Bimetallic Catalyst with Intumescent Flame Retardant on Flame Retardancy and thermal Stability of Polypropylene. Polym. Degrad. Stab. 129, 114-124. doi:10.1016/j.polymdegradstab.2016.04.006

Wang, P.-J., Liao, D.-J., Hu, X.-P., Pan, N., Li, W.-X., Wang, D.-Y., et al. (2019). Facile Fabrication of Biobased P N C-Containing Nano-Layered Hybrid: Preparation, Growth Mechanism and its Efficient Fire Retardancy in Epoxy. Polym. Degrad. Stab. 159, 153-162. doi:10.1016/ j.polymdegradstab.2018.11.024

Wang, Q., Li, J., and Winandy, J. (2004). Chemical Mechanism of Fire Retardance of Boric Acid on wood. Wood. Sci. Technol. 38 (5), 375-389. doi:10.1007/ s00226-004-0246-4

Wang, W., Xiao, J., Wei, X., Ding, J., Wang, X., and Song, C. (2014). Development of a New clay Supported Polyethylenimine Composite for CO2 Capture. Appl. Energ. 113 (6), 334-341. doi:10.1016/j.apenergy.2013.03.090

Wang, X., Romero, M. Q., Zhang, X.-Q., Wang, R., and Wang, D.-Y. (2015). Intumescent Multilayer Hybrid Coating for Flame Retardant Cotton Fabrics Based on Layer-By-Layer Assembly and Sol-Gel Process. RSC Adv. 5 (5), 10647-10655. doi:10.1039/c4ra14943b

Wang, Y., Ding, X., Chen, X., Chen, Z., Zheng, K., Chen, L., et al. (2017). Layer-bylayer Self-Assembly Photocatalytic Nanocoating on Cotton Fabrics as Easily Recycled Photocatalyst for Degrading Gas and Liquid Pollutants. Cellulose 24 (10), 4569-4580. doi:10.1007/s10570-017-1445-0

Xiong, Z., Zhang, Y., Du, X., Song, P., and Fang, Z. (2019). Green and Scalable Fabrication of Core-Shell Biobased Flame Retardants for Reducing
Flammability of Polylactic Acid. ACS Sustain. Chem. Eng. 7 (9), 8954-8963. doi:10.1021/acssuschemeng.9b01016

Xu, Q., Jin, C., Zachar, M., and Majlingova, A. (2013). Test Flammability of PVC Wall Panel with Cone Calorimetry. Proced. Eng. 62, 754-759. doi:10.1016/ j.proeng.2013.08.122

Ye, C. H., Zheng, Y. F., Wang, S. Q., Xi, T. F., and Li, Y. D. (2012). In Vitro corrosion and Biocompatibility Study of Phytic Acid Modified WE43 Magnesium alloy. Appl. Surf. Sci. 258 (8), 3420-3427. doi:10.1016/j.apsusc.2011.11.087

Yu, Y., Hou, J., Dong, Z., Wang, C., Lu, F., and Song, P. (2016). Evaluating the Flammability Performance of Portland Cement-Bonded Particleboards with Different Cement-wood Ratios Using a Cone Calorimeter. J. Fire Sci. 34 (3), 199-211. doi:10.1177/0734904116630758

Zeng, X., Lin, J., Cai, W., Lu, Q., Fu, S., Li, J., et al. (2021). Fabrication of Superhydrophilic PVDF Membranes by One-step Modification with Eco-Friendly Phytic Acid and Polyethyleneimine Complex for Oil-In-Water Emulsions Separation. Chemosphere 264 (1), 128395. doi:10.1016/j.chemosphere.2020.128395

Zhang, L., Yi, D., Hao, J., and Gao, M. (2020). One-step Treated wood by Using Natural Source Phytic Acid and Uracil for Enhanced Mechanical Properties and Flame Retardancy. Polym. Adv. Technol. 32, 1176-1186. doi:10.1002/pat.5165

Zhang, T., Yan, H., Shen, L., Fang, Z., Zhang, X., Wang, J., et al. (2014a). A Phosphorus-, Nitrogen- and Carbon-Containing Polyelectrolyte Complex: Preparation, Characterization and its Flame Retardant Performance on Polypropylene. RSC Adv. 4, 48285-48292. doi:10.1039/c4ra09243k

Zhang, T., Yan, H., Shen, L., Fang, Z., Zhang, X., Wang, J., et al. (2014b). Chitosan/ Phytic Acid Polyelectrolyte Complex: A green and Renewable Intumescent Flame Retardant System for Ethylene-Vinyl Acetate Copolymer. Ind. Eng. Chem. Res. 53 (49), 19199-19207. doi:10.1021/ie503421f

Zhang, X., Zhou, Z., Zhu, Y., Dai, J., Yu, Y., and Song, P. (2019). High-pressure Steam: A Facile Strategy for the Scalable Fabrication of Flattened Bamboo Biomass. Ind. Crops Prod. 129, 97-104. doi:10.1016/j.indcrop.2018.11.061

Zhang, Y., Zhang, X., Yu, Y., Che, W., Zhang, X., and Hou, J. (2020). Evaluating the Comprehensive Influences of Heat Treatment and Polydimethylsiloxane on Integrated Performance of Bamboo Timber. RSC Adv. 10 (71), 43438-43446. doi:10.1039/d0ra08713k

Zhang, Z., Ma, Z., Leng, Q., and Wang, Y. (2019). Eco-friendly Flame Retardant Coating Deposited on Cotton Fabrics from Bio-Based Chitosan, Phytic Acid and Divalent Metal Ions. Int. J. Biol. Macromol. 140, 303-310. doi:10.1016/ j.ijbiomac.2019.08.049

Conflict of Interest: PL was employed by the company Zhonghang Monitoring and Testing Technology Research Institute Co., Ltd.

The remaining authors declare that the research was conducted in the absence of any commercial or financial relationships that could be construed as a potential conflict of interest.

Publisher's Note: All claims expressed in this article are solely those of the authors and do not necessarily represent those of their affiliated organizations, or those of the publisher, the editors and the reviewers. Any product that may be evaluated in this article, or claim that may be made by its manufacturer, is not guaranteed or endorsed by the publisher.

Copyright $\odot 2021$ Lin, Jiang, Ru, Che, Zhang, Ma, Hou and Yu. This is an openaccess article distributed under the terms of the Creative Commons Attribution License (CC BY). The use, distribution or reproduction in other forums is permitted, provided the original author(s) and the copyright owner(s) are credited and that the original publication in this journal is cited, in accordance with accepted academic practice. No use, distribution or reproduction is permitted which does not comply with these terms. 